Portland State University

PDXScholar

\title{
Inclusive Planning to Evaluate Improved Non- Emergency Medical Transportation Services for Patients With End Stage Renal Disease
}

Jenny Liu

Portland State University, jenny.liu@pdx.edu

August Benzow

Portland State University

Follow this and additional works at: https://pdxscholar.library.pdx.edu/trec_reports

Part of the Health Policy Commons, Social Policy Commons, Transportation Commons, and the Urban Studies Commons

Let us know how access to this document benefits you.

\section{Recommended Citation}

Liu, Jenny, and August Benzow. Inclusive planning to evaluate improved non-emergency medical transportation services for patients with End Stage Renal Disease. NITC-SS-734. Portland, OR: Transportation Research and Education Center (TREC), 2014. https://doi.org/10.15760/trec.41

This Report is brought to you for free and open access. It has been accepted for inclusion in TREC Final Reports by an authorized administrator of PDXScholar. Please contact us if we can make this document more accessible: pdxscholar@pdx.edu. 


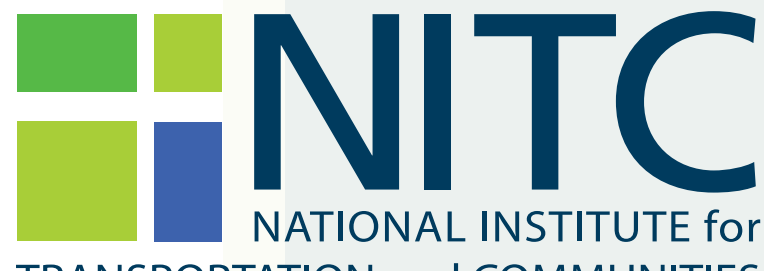

TRANSPORTATION and COMMUNITIES

\section{DRAFT FINAL REPORT}

\section{Evaluation Framework for Non-Emergency Medical Transportation Services for Patients with End-Stage Renal Disease}

\section{NITC-SS-734 December 2014}

NITC is the U.S. Department of Transportation's national university transportation center for livable communities.

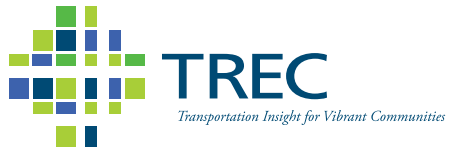




\section{EVALUATION FRAMEWORK FOR NON-EMERGENCY MEDICAL TRANSPORTATION SERVICES FOR PATIENTS WITH END-STAGE RENAL DISEASE}

\section{Draft Final Report}

NITC-SS-734

by

Jenny H. Liu, Ph.D.

August Benzow

Portland State University

\section{for}

National Institute for Transportation and Communities (NITC)

P.O. Box 751

Portland, OR 97207
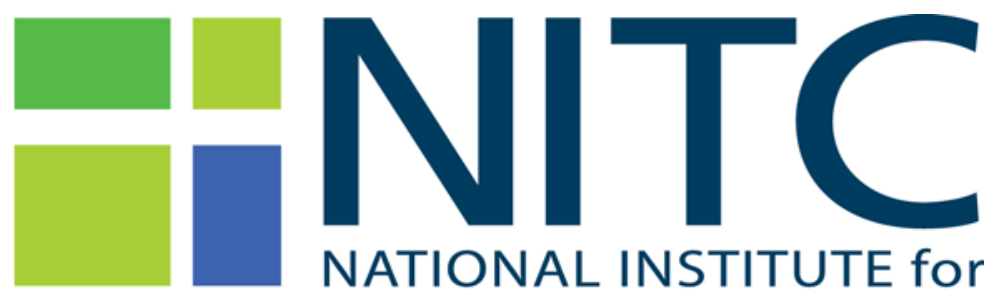

TRANSPORTATION and COMMUNITIES

December 2014 



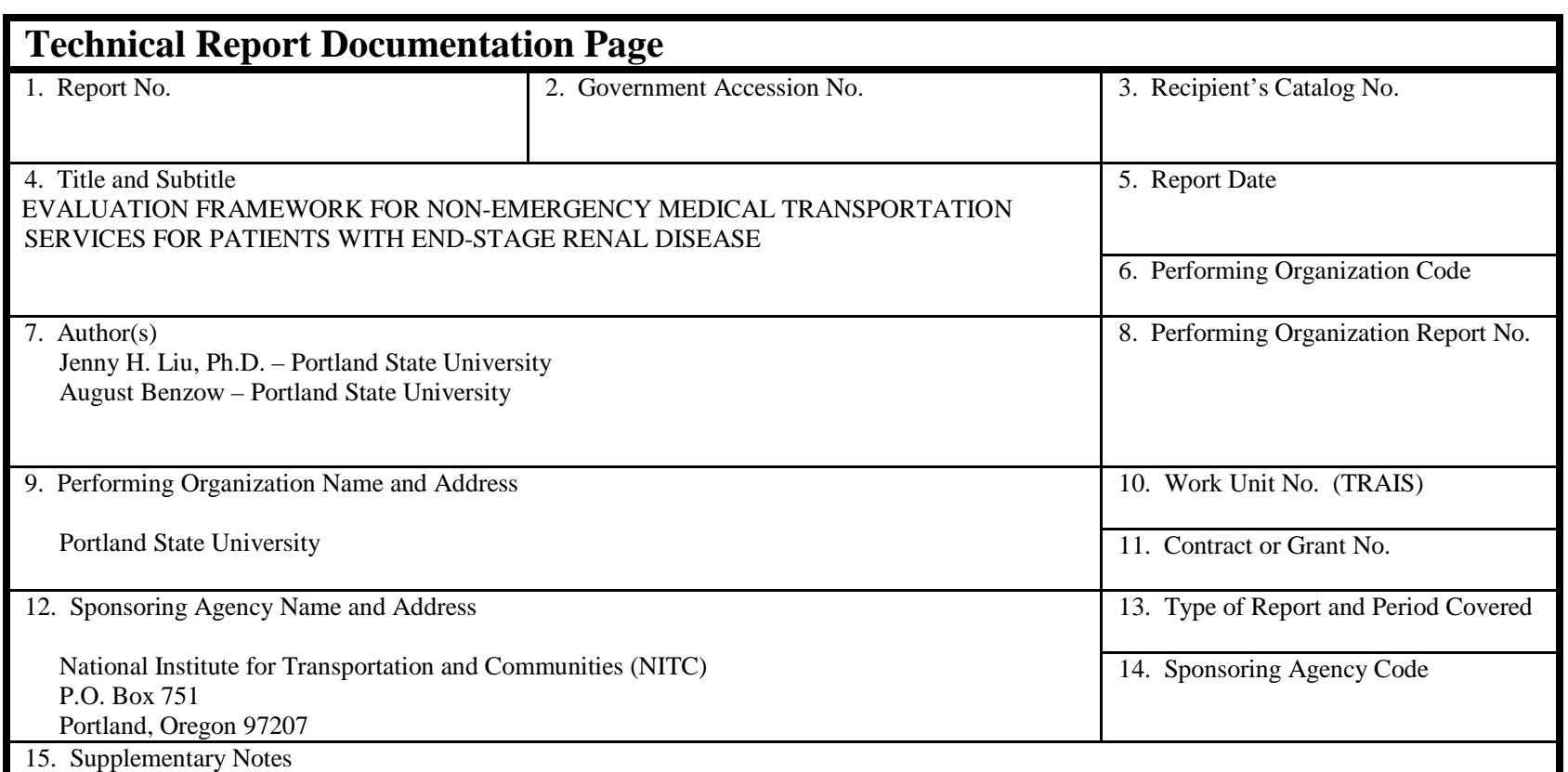

15. Supplementary Notes

16. Abstract

The objective of this project is to design a framework that could be used to evaluate the effectiveness and efficiency of non-emergency transportation services (NEMT) for better livability. In addition to the development of the framework, this project aimed to establish connections between Portland State University (PSU) researchers with regional connections involved in public health research, non-emergency medical transportation, medical services, and medical insurance provision. With the rising costs of transportation and medical costs generally in the United States, it is increasingly important to develop new tools and strategies to reduce these costs while maintaining and improving upon the level of care provided. Ultimately, the inability to afford NEMT can lead to missed appointments and reduced access to medical care for vulnerable populations, which in turn can lead to more trips to the emergency room and reduced quality of life. This impacts not only individuals, but the communities that these individuals are a part of.

A robust literature review and background research laid the groundwork for this project. This literature review provides an overview of the body of literature that analyzes how non-emergency medical transportation is provided in the United States and also highlights gaps in the existing research. Special attention is paid to the challenges of patients with end-stage renal disease (ESRD), who require routine NEMT service for dialysis appointments. The emerging focus on community-based participatory research (CBPR) is also discussed as a potential tool for better incorporating qualitative data into future analyses of the costs and benefits of providing NEMT. In this process, we identified key strategies for improving NEMT, including better coordination between dialysis clinics and NEMT providers, consideration of fixed-route transportation and improvements in dispatch technology.

We developed a framework for evaluating NEMT program changes that centers on a hybrid cost-benefit analysis matrix, modeled on a CBPR approach developed by Stevens et al. for their 2008 evaluation of an Australian childcare strategy. The matrix was refined via feedback from Ride Connection's advisory committee, and is tailored to many of the unique challenges facing NEMT programs. In conjunction with the hybrid costbenefit analysis framework, a preliminary patient survey instrument was developed to facilitate the collection of data to evaluate transportation policy or program changes for NEMT providers. These tools represent the first steps to researching, evaluating and improving NEMT for healthier and more livable communities.

\begin{tabular}{|c|c|c|c|}
\hline 17. Key Words & $\begin{aligned} 18 . \mathrm{I} \\
\mathrm{No} \\
\mathrm{WV}\end{aligned}$ & $\begin{array}{l}\text { bution Statement } \\
\text { rictions. Copies av } \\
\text { IITC.us }\end{array}$ & \\
\hline $\begin{array}{l}\text { 19. Security Classification (of this report) } \\
\text { Unclassified }\end{array}$ & $\begin{array}{l}\text { 20. Security Classification (of this page) } \\
\text { Unclassified }\end{array}$ & 21. No. of Pages & 22. Price \\
\hline
\end{tabular}





\section{ACKNOWLEDGEMENTS}

This project was funded by the National Institute For Transportation and Communities (NITC). The authors would also like to thank our partners at Ride Connection: Julie Wilcke, Chief Operating Officer, and Elaine Wells, Executive Director.

\section{DISCLAIMER}

The contents of this report reflect the views of the authors, who are solely responsible for the facts and the accuracy of the material and information presented herein. This document is disseminated under the sponsorship of the U.S. Department of Transportation University Transportation Centers Program in the interest of information exchange. The U.S. Government assumes no liability for the contents or use thereof. The contents do not necessarily reflect the official views of the U.S. Government and Portland State University. This report does not constitute a standard, specification, or regulation. 


\section{TABLE OF CONTENTS}

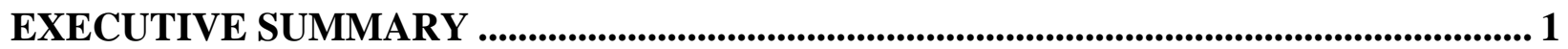

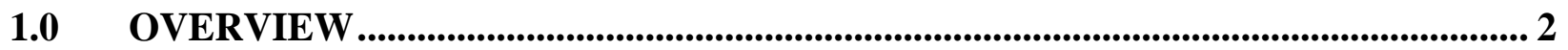

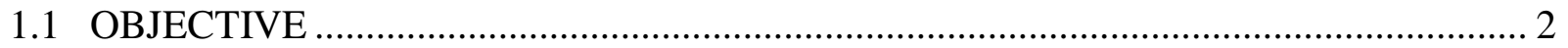

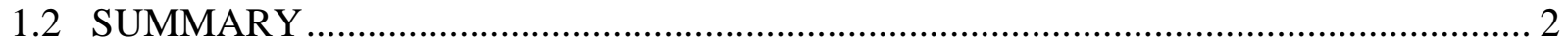

2.0 BACKGROUND \& LITERATURE ........................................................................... 4

2.1 NON-EMERGENCY MEDICAL TRANSPORTATION (NEMT) ................................ 5

2.1.1 Preventative Health Care ................................................................................ 5

2.1.2 Models for Providing NEMT to Medicaid Patients ................................................ 6

2.2 END-STAGE RENAL DISEASE (ESRD) ........................................................ 7

2.2.1 End-Stage Renal Disease in the United States.................................................... 7

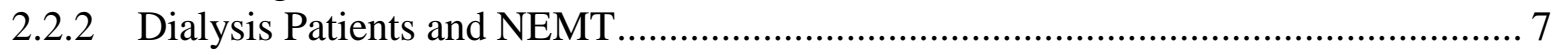

2.2.3 Unique Transportation Challenges for Dialysis Patients ....................................... 8

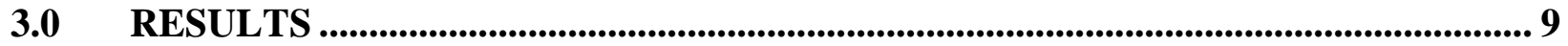

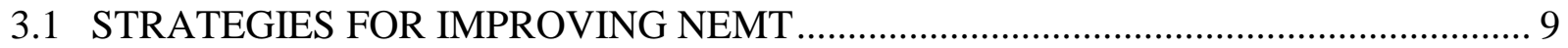

3.2 COST-BENEFIT ANALYSIS FOR NEMT \& BEST PRACTICES .............................. 10

3.2.1 Hybrid Cost-Benefit Analysis Framework through a Community-based Participatory

Research (CBPR) Approach ................................................................................ 10

3.2.2 Discussion of Cost-Benefit Analysis for NEMT .............................................. 11

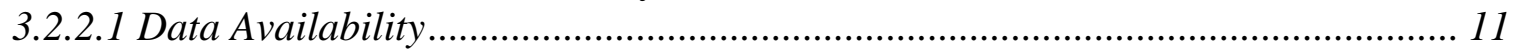

3.2.2.2 Assigning Monetary Value to Non-Monetary Costs and Benefits ........................ 11

3.2.2.3 Assessing Qualitative Value in a NEMT CBA ................................................. 12

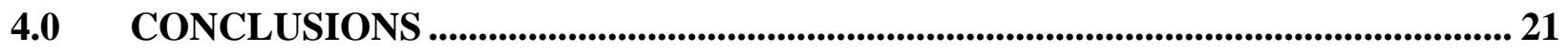

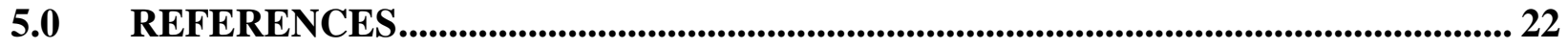




\section{EXECUTIVE SUMMARY}

The initial objective of this project was to design a framework that could be used to evaluate the effectiveness and efficiency of non-emergency transportation services (NEMT) for better livability. In addition to the development of the framework, this project aimed to establish connections between Portland State University (PSU) researchers with regional connections involved in public health research, non-emergency medical transportation, medical services, and medical insurance provision. With the rising costs of transportation and medical costs generally in the United States, it is increasingly important to develop new tools and strategies to reduce these costs while maintaining and improving upon the level of care provided. Ultimately, the inability to afford NEMT can lead to missed appointments and reduced access to medical care for vulnerable populations, which in turn can lead to more trips to the emergency room and reduced quality of life. This impacts not only individuals, but the communities that these individuals are a part of.

A robust literature review and background research laid the groundwork for this project. This literature review provides an overview of the body of literature that analyzes how nonemergency medical transportation is provided in the United States and also highlights gaps in the existing research. Special attention is paid to the challenges of patients with end-stage renal disease (ESRD), who require routine NEMT service for dialysis appointments. The emerging focus on community-based participatory research (CBPR) is also discussed as a potential tool for better incorporating qualitative data into future analyses of the costs and benefits of providing NEMT. In this process, we identified key strategies for improving NEMT, including better coordination between dialysis clinics and NEMT providers, consideration of fixed-route transportation and improvements in dispatch technology.

We developed a framework for evaluating NEMT program changes that centers on a hybrid costbenefit analysis matrix, modeled on a CBPR approach developed by Stevens et al. for their 2008 evaluation of an Australian childcare strategy. The matrix was refined via feedback from Ride Connection's advisory committee, and is tailored to many of the unique challenges facing NEMT programs. In conjunction with the hybrid cost-benefit analysis framework, a preliminary patient survey instrument was developed to facilitate the collection of data to evaluate transportation policy or program changes for NEMT providers. These tools represent the first steps to researching, evaluating and improving NEMT for healthier and more livable communities.

In addition to the development of the framework, the project has stimulated an active dialogue between the PI and graduate students at PSU with regional partners at Ride Connection, Providence Center for Outcomes Research and Education (Providence CORE), Trimet, Upstream Health and Health Share of Oregon. Research grant proposals involving this regional network of researchers are ongoing as well. 


\subsection{OVERVIEW}

\subsection{OBJECTIVE}

The initial objective of this project was to design a framework that could be used to evaluate the effectiveness and efficiency of non-emergency transportation services (NEMT). In addition to the development of the framework, this project aimed to establish connections between Portland State University (PSU) researchers with regional connections involved in public health research, non-emergency medical transportation, medical services, and medical insurance provision. With the rising costs of transportation and medical costs generally in the United States, it is increasingly important to develop new tools and strategies to reduce these costs while maintaining and improving upon the level of care provided. Ultimately, the inability to afford NEMT can lead to missed appointments and reduced access to medical care for vulnerable populations, which in turn can lead to more trips to the emergency room and reduced quality of life. This impacts not only individuals, but the communities that these individuals are a part of.

\subsection{SUMMARY}

A robust literature review and background research laid the groundwork for this project. This literature review provides an overview of the body of literature that analyzes how nonemergency medical transportation is provided in the United States and also highlights gaps in the existing research. Special attention is paid to the challenges of patients with end-stage renal disease (ESRD). These patients need routine NEMT service for dialysis appointments and therefore are representative of the successes and failures of the established NEMT system. The emerging focus on community-based participatory research (CBPR) is also discussed as a potential tool for better incorporating qualitative data into future analyses of the costs and benefits of providing NEMT. In this process, key strategies for improving NEMT were identified and incorporated into the development of an analysis framework.

This project focused on generating tools that can be used not only by the client with which the researchers partnered, Ride Connection, but similar transportation providers nationwide. As a non-profit, Ride Connection has been successful in providing affordable transportation service to its clients through cost-cutting strategies that are not available to larger transit agencies, such as the use of volunteer drivers, while at the same time maintaining a high level of customer service.

In March 2014, Ride Connection received funding to launch a pilot project that would improve the level of service for dialysis patients while generating only minimal cost increases. The core objective of this pilot project is to better coordinate between the clinics that dialysis patients must visit three to four times a week in order to receive life-sustaining dialysis and the transportation providers. We developed a framework for evaluating NEMT program changes that centers on a hybrid cost-benefit analysis matrix, modeled on a CBPR approach developed by Stevens et al. for their 2008 evaluation of an Australian childcare strategy. Much like Ride 
Connection's pilot project, the Australian childcare strategy needed to be measured on a qualitative scale as well as a quantitative one in order to incorporate benefits that do not have a clear metric, such as increased well-being for clients.

The matrix developed for this project, while relying heavily on precedents provided by the literature, differs in that it is intended to serve as a tool for evaluating a program both before and after its implementation. It is also especially tailored to many of the challenges facing NEMT programs. The evaluation criteria presented in the matrix is intended to be widely applicable to a wide range of NEMT programs, but some of the criteria may not be relevant to a particular program or additional criteria may be needed. In short, this matrix is a starting point for evaluating a NEMT-related strategy, but is intended to be used in conjunction with other tools and serve as a framework for a cost-benefit analysis of Ride Connection's pilot project once it is completed.

The next logical step from the development of the evaluation matrix was to develop a preliminary patient survey instrument (Figure 1) that serves to establish a before-and-after snapshot of how the pilot project impacts patients who have chosen to participate. This is essential for tracking changes in the quality of life for patients, and being able to provide evidence of qualitative improvements as a result of the project. These qualitative improvements will in turn augment the hybrid cost-benefit analysis framework and give precedence to benefits that lack an economic metric.

While this project has been successful in creating tools that will be useful for evaluating strategies to improve NEMT, like the one being implemented by Ride Connection, more work still needs to be done in order to ensure the successful application of these tools. Once Ride Connection's pilot project is completed, it will be possible to do a thorough analysis using these tools and make modifications as needed. This, in turn, will ensure the adaptability of these tools and their continued usefulness in enhancing NEMT programs. 


\subsection{BACKGROUND \& LITERATURE}

Most the literature that discusses NEMT is focused on the provision of Medicaid, with many studies choosing to focus on funding structures, usually at the state level. The mechanics of transportation brokerages and how they can best be implemented either regionally or at the state level is a dominant topic in much of the literature on Medicaid NEMT. Only a handful of studies directly focus on the impacts of the way in which NEMT is provided to patients. Although literature discussing Medicaid NEMT is the most prevalent, it is still not substantial. According to Rosenbaum (2009):

The most recent comprehensive state survey to determine how states are administering NEMT was done in 2003, and most studies have been carried out by companies serving as transportation brokers themselves or associations representing transportation providers. The small amount of scholarly research that does exist tends to show that NEMT is a utilized and necessary benefit.

The literature shows that not only is NEMT “utilized and necessary," but that demand for NEMT is increasing, largely due to an aging population. It remains uncertain whether or not the existing system model is adequate for providing to NEMT to everyone who needs it.

Literature that discusses NEMT concerns for non-Medicaid patients, either those on Medicare or those using some type of private insurance or no insurance at all, is practically non-existent. A recent study completed by Ride Connection, a non-profit NEMT transportation provider in Portland, OR, found that only about 20 percent of new patients were using Medicaid. If this data is representative of NEMT transportation providers in other states and regions, the literature will need to develop a stronger focus on the challenges of providing NEMT to patients who do not have Medicaid. Research that explores the impacts of the Affordable Care Act on NEMT practices will also be highly relevant.

Perhaps the most significant oversight in the existing body of NEMT literature is the lack of data collected from patients and research strategies that promote community buy-in. While some Medicaid assessments did collect data from patients, as in the Medical Transportation Systems Review, completed by the University of Iowa Public Policy Center (2008), the data was collected using phone and web-based surveys, versus more robust participation strategies such as focus groups and in-person interviews with patients. The questions in these surveys were mainly intended to determine whether or not there was unmet demand for NEMT and did not capture non-Medicaid patients or establish any framework for a collaborative process to improve NEMT service. Therefore, this literature review will include examples of community-based participatory research (CBPR) and efforts to give qualitative data a strong role in a standard cost-benefit analysis.

The following sections discuss current research in non-emergency medical transportation, preventative health care in the context of NEMT, and models of NEMT provision in Medicare, with a focus on the unique transportation challenges for end-stage renal disease (ESRD) patients. 


\subsection{NON-EMERGENCY MEDICAL TRANSPORTATION (NEMT)}

Providing NEMT to the transportation-disadvantaged is an essential service that can increase the quality of life for patients and reduce emergency room visits. It is estimated that 3.5 million Americans miss non-emergency medical appointments due to transportation challenges (HughesCromwick et al., 2005), a number which is likely to increase because of an aging population. This literature review, therefore, is intended to provide a snapshot of current research into NEMT best practices with a special focus on transportation for dialysis patients. The first section of this literature review is intended to provide an overview of current research into NEMT practices and provides some background information about NEMT provision, especially within the Medicaid and Medicare programs. The second section looks at patients with end-stage renal disease (ESRD) and consequently need to be transported to a clinic twice a week or more for dialysis. Because these patients are dependent on NEMT for life-saving medical treatment, their transportation challenges provide a relevant case study for the entire transportation-challenged population. The final section explores the existing literature on strategies for improving the effectiveness and efficiency of NEMT practices, with special attention paid to the challenges of calculating costs and benefits and the benefits of community-based participatory research approach (CBPR).

Medicaid expenditures for NEMT total \$1.75 billion a year with about 10 percent of the Medicaid population dependent on Medicaid for paying NEMT costs (Rafael, 2001; Kim et al., 2009). Although this constitutes 20 percent of federal transportation expenditures (Rosenbaum et al., 2009), NEMT contributes to only 1 percent of total Medicaid expenditures and, therefore, tends to get less attention than other Medicaid expenditures. When deciding how to fund and implement Medicaid NEMT, states can choose to classify the service delivery model as either an administrative service expense or as an optional medical service expense (Stefl \& Newsom, 2003). This classification, in turn, determines the amount that the federal government reimburses. Administrative expenses get reimbursed at 50 percent, whereas the reimbursement for medical expenses is usually higher, ranging from 50 percent to 83 percent, based on a per capita income calculation. Because states get more money from the federal government for medical expenses, there is a clear incentive to classify NEMT as such. However, if they classify NEMT as a medical expense there are additional guidelines that states must follow, such as freedom of choice for clients in choosing a provider and offering the same level of service to clients with comparable needs, which can add to the cost of providing NEMT. As a result, states must choose between the flexibility of administrative expenses and the better reimbursement rate of medical expenses. Any state that chooses to use a brokerage system for Medicaid NEMT, discussed below, has to classify it as an administrative expense, unless given a waiver. It is also possible to use a combination of the two funding types.

\subsubsection{Preventative Health Care}

The literature shows that providing a sufficient level of NEMT to meet the needs of each patient reduces healthcare costs overall (Cromwick et al., 2005). The number of non-emergency trips to the hospital by a community typically indicates a lack of NEMT options. Patients who have good access to affordable NEMT are more likely to make preventive medical appointments and less likely to make emergency trips to the hospital (Wilkins et al., 2012). 
Unlike Medicaid, Medicare only covers emergency trips and does not provide funding for NEMT. Burkhardt provides evidence that this it is highly cost-inefficient in addition to negatively impacting the health of Medicare recipients. His estimate suggests that Medicare could save \$300 million annually by providing funding for NEMT (2006). Patients who are not able to afford transportation to the hospital for medical appointments rely on emergency vehicles when their condition becomes severe rather than utilizing non-emergency medical transportation on a regular basis.

\subsubsection{Models for Providing NEMT to Medicaid Patients}

There are four models for providing NEMT to Medicaid patients:

1. Administrative Manager Model

2. Managed Care Model

3. Transportation Brokerage

4. Broker Operator Model

The administrative manager model avoids extensive bureaucracy by having an administrative manager coordinate NEMT for a given region in a state. Alabama, for example, has 10 managers coordinating NEMT throughout the state. The limitation of this model is that these managers typically do not have substantial resources due to the lack of bureaucratic manpower. Under the managed care model, responsibility for NEMT is delegated to Managed Care Organizations (MCOs, formerly known as HMOs). These MCOs are a network of care providers and help to facilitate better coordination between different health institutions, which can resolve issues such as missed appointments and timing transportation with appointments. States can opt for either a risk-based option, whereby a MCO is paid a set amount each month for each member needing NEMT, or a non-risk-based option, whereby MCOs are reimbursed for NEMT service and are not at financial risk for providing this service (Non-emergency medical, 2008).

More and more state Medicaid programs have switched to some kind of brokerage system to provide NEMT, especially following the 2006 Deficit Reduction Act, which allowed states "to establish a non-emergency medical transportation brokerage system without regard to statutory requirements for comparability, statewideness and freedom of choice” (73 FR 77519 2008, quoted in Rosenbaum et al., 2009). A brokerage payment system can either be capitated, where brokerage payments by the state are capped at certain percentage, or utilize a flat fee plus an administrative fee (McCann \& Nichols, 2005). With either payment brokerage method, the state pays a broker a negotiated flat rate for each eligible patient that requires NEMT and the broker in turns provides medical transportation for every eligible patient.

A brokerage system is able to share rides across MCO boundaries and, therefore, has the potential to be more efficient. Overall this system has been less expensive for states (Kim et al., 2009). Brokers are incentivized to reduce costs and increase operating efficiencies because the rate they are receiving is fixed; therefore, the return on their investment is greater if they can provide the service at the lowest cost possible (Stefl \& Newsom, 2003). This impetus for efficiency would not be so predominant if NEMT trips were directly provided by the state. At the same time there is also the possibility that a broker will provide sub-standard service in order to 
maximize profit. Even in cases where the broker has the best of intentions, it is easy for mismanagement to lead to substantial losses if the cost of providing NEMT exceeds the flat rate paid to the broker (McCann \& Nichols, 2005).

By using volunteer drivers and other cost-saving strategies, the Portland-based non-profit Ride Connection has been able to provide NEMT trips for about 32 percent of the cost of comparable trips using Trimet, the primary transportation provider for the Portland region (Burkhardt, 2006). The most prevalent alternative to a capitated brokerage system is a fee-for-service voucher system in which patients are given a voucher that they can use to pay for transportation service from a variety of providers. However, the administrative cost of voucher systems are typically higher, making it more expensive than a brokerage system, and it promotes overuse and abuse. As a consequence, a voucher system requires more oversight and more caseworkers who must determine whether patients are eligible for the vouchers (Wilson et al., 2000).

With the broker as operator model, the transportation brokers are also the transportation operators. This can lead to conflicts of interest when brokers contract in-house instead of contracting with a diversity of providers that are selected through a fair bidding process.

\subsection{END-STAGE RENAL DISEASE (ESRD)}

\subsubsection{End-Stage Renal Disease in the United States}

Twenty-six million Americans suffer from kidney disease and of those, 571,000 suffer from ESRD, according to 2009 statistics (Bogren, 2011). In 1980, only 60,000 people were receiving treatment for ESRD. The steady increase in ESRD cases can be attributed to an aging population and increases in diseases that lead to ESRD, namely diabetes and hypertension, which together account for 65 percent of ESRD cases (McCann \& Nichols, 2005). Treatment for ESRD typically requires either a kidney transplant or a dialysis routine. There two types of dialysis are peritoneal dialysis (PD) and hemodialysis dialysis (HD). PD involves introducing a fluid into the abdominal cavity to draw out waste and is typically done at home. HD requires hooking up a patient to an artificial kidney machine; therefore, a patient undergoing an HD routine must be transported to a hospital or dialysis clinic. The majority, 85 to 90 percent, of ESRD patients are treated using HD (McCann \& Nichols, 2005). For the past 40 years or so, the standard HD regimen has been three four-hour sessions a week. However, recent studies have suggested that six 2.5-hour sessions would improve health and quality of life (Bogren, 2011).

\subsubsection{Dialysis Patients and NEMT}

Trips to and from the hospital for dialysis patients are, in most instances, classified as NEMT. Most dialysis patients have to journey to the clinic at least three times a week in order to receive treatment. One study found that patients who travelled longer than 60 minutes to a dialysis appointment had a 20 percent greater risk of death compared to those who reached their appointments in 15 minutes or less (Diamant et al., 2010). Dialysis trips can last up to four hours (Bogren, 2011). Many dialysis patients are not covered by Medicaid and, therefore, have to find other ways to pay for the trips to the dialysis clinic. Those who are too ill to utilize a fixed route 
have to turn to community organizations that coordinate volunteer drivers or family members and friends.

\subsubsection{Unique Transportation Challenges for Dialysis Patients}

Because HD treatment requires the use of anti-coagulant drugs, patients are at risk of bleeding excessively immediately after completing the treatment. If bleeding occurs during transport the driver has to return to the hospital or clinic, otherwise the bleeding could become life-threatening (McCann \& Nichols, 2005). A Canadian study that used data collected from patients who underwent HD from 1990 to 2000 found that patients who lived further away from their nephrologist had a higher rate of death from infection (Tonelli et al., 2007). An estimated 37 percent of dialysis patients use a wheelchair or walker, which creates additional transportation challenges (Rosenbaum et al., 2009). 


\subsection{RESULTS}

\subsection{STRATEGIES FOR IMPROVING NEMT}

Through our review of the existing literature, as well as consultation with Ride Connection and its advisory committee, we found several key strategies for non-emergency medical transportation (NEMT) that may improve transportation provision, provide better outcomes for patients, and result in better cost effectiveness. Any changes in NEMT provision or program administration may be then evaluated through the hybrid cost-benefit analysis framework presented in the following section.

\section{Better Coordination between Dialysis Clinics and NEMT Providers}

Coordination between dialysis clinics and medical transporters is critical in order to ensure the efficiency of the transportation service. If patients who live in close proximity to each other are being scheduled dialysis at different times, this can lead to enormous transportation cost overruns (McCann \& Nichols, 2005). There are many opportunities to reduce medical transportation costs by improving communication between clinics and transporters. As the number of dialysis patients continues to increase, it will be economically feasible to open more clinics, which will relieve some of the burden on medical transporters. A minimum of 25 patients are needed in order to provide sufficient revenue for a clinic to open. New clinics also need to be sited carefully so as to maximize the efficiency of existing transportation infrastructure (McCann \& Nichols, 2005).

\section{Transferring Patients to Fixed Route Transportation}

Encouraging fixed route transportation is another cost-saving measure. Several case studies have shown that switching some Medicaid clients from paratransit to fixed route saved, on average, \$2 million annually (Burkhardt, 2006). The Minnesota Non-Emergency Transit's “On the Move” program provide an assessment of individuals currently using non-fixed route transit and, when appropriate, offered training for how to successfully navigate fixed route transit. Doing so provided NEMT users with greater independence and flexibility while providing substantial cost savings (Zhao, 2013). The addition of feeder or circulator routes that collect passengers in a given area and drop them off at a bus or transit line can further enhance the functionality of fixed routes. Another option is to use a hybrid option such as a deviated fixed route that will deviate from a fixed route for special reasons, such as to pick up a patient or stop at a doctor's office and then return to the fixed route again (McCann \& Nichols, 2005). The effectiveness and cost savings of a shift towards fixed routes works best in areas where a brokerage system is already in place, which can provide financial backing and bureaucratic infrastructure (O’Connell et al., 2002).

\section{Improved Dispatch Technology}

Case studies conducted in Minnesota found that there were substantial benefits from investing funds in improving the dispatch technology used by NEMT providers. In Hubbard County, MN, 
the Hubbard County Heartland Express contracted with Paul Bunyan Transit for dispatch services. This access to more sophisticated technology reduced driver distraction and increased efficiency within the service area (Zhao, 2013).

\subsection{COST-BENEFIT ANALYSIS FOR NEMT \& BEST PRACTICES 3.2.1 Hybrid Cost-Benefit Analysis Framework through a Community-based
Participatory Research (CBPR) Approach}

Gathering valuable input from the transportation-disadvantaged population requires a robust participatory process that emphasizes community engagement. Therefore, a CBPR approach is particularly effective for assessing the outcomes of a NEMT strategy, and for determining whether or not the strategy substantially benefits the targeted population. Many of those who are transportation-disadvantaged are also disempowered in other ways and lack the resources necessary to directly impact policy. Proper integration of local knowledge and local conditions is essential for securing a strategy's success. CBPR addresses many of the challenges of including input from underrepresented communities by providing a toolkit for partnering with community members, integrating cultural values, enhancing program sustainability after an intervention is finished, and democratizing the science underlying a program (Wallerstein \& Duran, 2010).

In 2008, Stevens et al. evaluated the Australian Government's Stronger Families and Communities Strategy 2000-2004, which was a strategy broadly structured to assist disadvantaged families and increase their future opportunities, with the bulk of it focusing on improving childcare. This strategy is comparable to many interventions intended to improve NEMT options in that its benefits are more likely to be qualitative and, in instances where they are quantitative, accurate measurements can be challenging. This strategy relied heavily on a CBPR approach to collect data from community members in order to build a robust analysis of qualitative benefits and costs. They use a framework similar to Ziller and Phibbs (2003) where costs include both resource expenditures and negative outcomes, while benefits include either negative outcomes avoided or the achievement of positive outcomes. For example, additional hours worked by a NEMT driver can be a cost for the transportation provider, but can also provide positive benefits for the client.

The hybrid cost-benefit analysis matrix is presented in Table 1. While this framework relies heavily on precedents provided by the literature, it differs in that it is intended to serve both as a tool for evaluating a program before and after its implementation. It is also especially tailored to many of the challenges facing NEMT programs, and has incorporated feedback from an advisory committee at Ride Connection. The evaluation criteria presented in the matrix is intended to be widely applicable to a wide range of NEMT programs, but some of the criteria may not be relevant to a particular program or additional criteria may be needed. In short, this matrix is a starting point for evaluating a NEMT-related strategy, but is intended to be used in conjunction with other tools.

In partnership with Ride Connection, we also developed a preliminary patient survey instrument that would assist the NEMT provider with collecting essential patient information to evaluate its 
program and services. The instrument, shown in Figure 1, is designed to be utilized in conjunction with the matrix framework.

\subsubsection{Discussion of Cost-Benefit Analysis for NEMT}

The proposed hybrid cost-benefit analysis framework may require additional customization depending on specific programs being evaluated or policy changes being implemented. Additional issues and considerations regarding such a framework are discussed below, and may indicate areas for future research.

\subsubsection{Data Availability}

There are several challenges for any cost-benefit analysis of medical transportation dialysis. The first is the lack of available data. The two most commonly used studies for determining health impacts of NEMT are the National Health Interview Survey and the Medical Expenditure Panel Survey. Both of these studies fail to explicitly address NEMT, instead opting for broad questions about “transportation difficulties.” Moreover, there is neither a clear definition of "transportation-disadvantaged" nor a clear estimate as to how many individuals should be classified as such. A single NEMT trip can also address multiple health concerns, making it challenging to analyze the transportation practices for a single disease. Furthermore, many patients using NEMT have multiple conditions that often overlap and interact. Therefore, it can be argued in some instances that treating one disease improves the condition of another (Cromwick et al., 2005).

\subsubsection{Assigning Monetary Value to Non-Monetary Costs and Benefits}

Cost-benefit analyses (CBA) also face the difficulty of assigning monetary value to health improvements and therefore imply a certain degree of arbitrariness on the part of the researcher (Cromwick et al., 2005a). For this reason, Cromwick recommends a costeffective analysis (CEA), which measures the effectiveness-per-unit- cost instead of comparing cost to cost. One way to calculate a CEA for a health intervention is to calculate the Quality Adjusted Life Year (QALY), which combines morbidity and mortality, and then look at the effect of input cost on the QALY for a treatment. Although a CEA avoids assigning monetary value to all health indicators, as would be the case with a CBA, it still requires the ethical challenge of determining what cost input qualifies as effective.

It is also difficult, in some cases, to differentiate between costs and benefits, especially in the healthcare field. An intervention strategy can be seen as benefitting a patient because the patient does not have to use a particular care option as much due to improved health. This intervention can also be interpreted as a reduced cost, though, because less money is being spent to provide the care option in question (Cromwick et al., 2005) 


\subsubsection{Assessing Qualitative Value in a NEMT CBA}

Perhaps the biggest challenge for performing a CBA of strategies to improve NEMT practices is ensuring that qualitative data that is difficult or impossible to assign a monetary value is given equal standing alongside quantitative data in the analysis.

Programs to improve NEMT are often tailored to fit the needs of a particular locality, and must be responsive to evolving needs and opportunities throughout the implementation process. This means that they tend to be more fluid and open-ended, and it can be challenging to assess these programs. Rogers, Stevens and Boymal identify three common responses to this challenge (2009). One is to turn the program into a more standard intervention and make it less molded to local needs. Although this makes a program easier to measure, it sacrifices many of its nuances and potential benefits rather than trying to improve the assessment methodology. A second response is to not attempt a CBA at all, and instead only use a CBA for a program where there are clear quantifiable costs. This is not a viable option because it makes the program in question less competitive for funding. The third most common response is to use high-level outcome measures, such as well-being indicators, which have their own set of challenges, such as being linked to a particular geographic area for social indicator data.

Rogers, Stevens and Boymal (2009) build on a CBA matrix approach developed by Ziller and Phibbs (2003). The Ziller and Phibbs model combines a participatory framework with a CBA that does not quantify all costs and benefits, making it impossible to calculate cost-benefit ratios. The matrix itself was completed entirely through a participatory process. Rogers, Stevens and Boymal make four modifications to the Ziller and Phibbs model:

1. They use other information besides input from the participatory process to refine the analysis.

2. Verbal information was only gathered from managers and staff involved in implementation; questionnaires were used to gather information from additional stakeholders.

3. Video conferencing was favored over face-to-face interviews.

4. They ignored the distinction between financial and non-financial benefits, and instead categorized costs as either resources used or negative outcomes and benefits as either positive or negative outcomes.

Because the Rogers, Stevens and Boymal model makes no attempt to quantify costs or benefits, it does not even attempt to provide a cost-benefit ratio or net benefit. The authors contend that their non-financial analysis can be used as the first stage in a process, wherein costs and benefits are monetized whenever possible. Or, alternatively, it can be used as is and compared to similar analyses that focus on outcomes instead of financial tallies. 
Table 1 - Hybrid Cost-Benefit Evaluation Matrix (Filled in for a sample Proposed Ride Connection Pilot Project)

\begin{tabular}{|c|c|c|c|c|c|}
\hline & $\begin{array}{l}\text { Potential } \\
\text { Positive } \\
\text { Outcomes }\end{array}$ & $\begin{array}{l}\text { Potential } \\
\text { Negative } \\
\text { Outcomes }\end{array}$ & $\begin{array}{l}\text { Negative } \\
\text { Outcomes } \\
\text { Avoided }\end{array}$ & $\begin{array}{l}\text { No } \\
\text { Measurable } \\
\text { Impact/ Data } \\
\text { Not Available }\end{array}$ & $\begin{array}{l}\text { Resources Expended (e.g. time, } \\
\text { costs both monetary and non- } \\
\text { monetary for each level, staffing, } \\
\text { other resources) }\end{array}$ \\
\hline \multicolumn{6}{|l|}{ Individuals/Clients } \\
\hline $\begin{array}{l}\text { Does the intervention } \\
\text { affect a client's QALY }{ }^{1} \text { ? }\end{array}$ & +++ & & $\checkmark \checkmark \checkmark$ & & \\
\hline $\begin{array}{l}\text { Does the intervention } \\
\text { affect the level of service } \\
\text { provided? }\end{array}$ & +++ & & & & \\
\hline $\begin{array}{l}\text { Is the client being } \\
\text { hospitalized less due to } \\
\text { fewer missed appointments } \\
\text { as a result of transportation } \\
\text { issues? }\end{array}$ & +++ & & & & \\
\hline $\begin{array}{l}\text { Does the intervention } \\
\text { affect the cost of } \\
\text { transportation for clients? }\end{array}$ & & -- & & & \\
\hline $\begin{array}{l}\text { Does the intervention } \\
\text { affect power relations } \\
\text { between the client and the } \\
\text { provider? }\end{array}$ & ++ & & & & \\
\hline $\begin{array}{l}\text { Does the intervention } \\
\text { affect the client's } \\
\text { knowledge of how his or } \\
\text { her care is provided? }\end{array}$ & & & & $X$ & \\
\hline $\begin{array}{l}\text { Does the intervention } \\
\text { affect civic participation } \\
\text { for the client? }\end{array}$ & & & & $X$ & \\
\hline
\end{tabular}

${ }^{1}$ QALY (Quality Adjusted Life Year) is a HRQoL (Health Related Quality of Life) metric. 


\begin{tabular}{|c|c|c|c|c|c|}
\hline & $\begin{array}{l}\text { Potential } \\
\text { Positive } \\
\text { Outcomes }\end{array}$ & $\begin{array}{l}\text { Potential } \\
\text { Negative } \\
\text { Outcomes }\end{array}$ & $\begin{array}{l}\text { Negative } \\
\text { Outcomes } \\
\text { Avoided }\end{array}$ & $\begin{array}{l}\text { No } \\
\text { Measurable } \\
\text { Impact/ Data } \\
\text { Not Available } \\
\end{array}$ & $\begin{array}{l}\text { Resources Expended (e.g. time, } \\
\text { costs both monetary and non- } \\
\text { monetary for each level, staffing, } \\
\text { other resources) }\end{array}$ \\
\hline \multicolumn{6}{|l|}{ Care Providers (Clinic) } \\
\hline $\begin{array}{l}\text { How does the intervention } \\
\text { affect the workload for } \\
\text { care providers? }\end{array}$ & & - - & & & \\
\hline $\begin{array}{l}\text { Does the intervention } \\
\text { affect the efficiency of care } \\
\text { providers? }\end{array}$ & ++ & & & & \\
\hline $\begin{array}{l}\text { Do care providers spend } \\
\text { extra time addressing } \\
\text { transportation issues? }\end{array}$ & & -- & & & \\
\hline $\begin{array}{l}\text { Do care providers become } \\
\text { frustrated by extra time } \\
\text { spent addressing } \\
\text { transportation issues? }\end{array}$ & & -- & & & \\
\hline \multicolumn{6}{|l|}{ Community } \\
\hline $\begin{array}{l}\text { Does intervention affect } \\
\text { community perceptions? }\end{array}$ & & & & $\mathrm{X}$ & \\
\hline $\begin{array}{l}\text { How does the intervention } \\
\text { affect social capital within } \\
\text { the community? }\end{array}$ & & & & $X$ & \\
\hline $\begin{array}{l}\text { How does the intervention } \\
\text { affect the role of clients in } \\
\text { community? }\end{array}$ & & & & $\mathrm{X}$ & \\
\hline
\end{tabular}




\begin{tabular}{|c|c|c|c|c|c|}
\hline & $\begin{array}{l}\text { Potential } \\
\text { Positive } \\
\text { Outcomes }\end{array}$ & $\begin{array}{l}\text { Potential } \\
\text { Negative } \\
\text { Outcomes }\end{array}$ & $\begin{array}{l}\text { Negative } \\
\text { Outcomes } \\
\text { Avoided }\end{array}$ & $\begin{array}{l}\text { No } \\
\text { Measurable } \\
\text { Impact/ Data } \\
\text { Not Available }\end{array}$ & $\begin{array}{l}\text { Resources Expended (e.g. time, } \\
\text { costs both monetary and non-- } \\
\text { monetary for each level, staffing, } \\
\text { other resources) }\end{array}$ \\
\hline \multicolumn{6}{|c|}{ Transportation Provider } \\
\hline \multicolumn{6}{|c|}{$\begin{array}{l}\text { How does the intervention } \\
\text { affect costs for } \\
\text { transportation providers? }\end{array}$} \\
\hline $\begin{array}{l}\text { How does the intervention } \\
\text { affect the provision of } \\
\text { NEMT? }\end{array}$ & +++ & & & & \\
\hline \multicolumn{6}{|l|}{ Government } \\
\hline $\begin{array}{l}\text { Does the intervention } \\
\text { affect the cost of service } \\
\text { for government? }\end{array}$ & & - - & & & \\
\hline $\begin{array}{l}\text { Can this model be applied } \\
\text { in different jurisdictions? }\end{array}$ & ++ & & & & \\
\hline $\begin{array}{l}\text { Does the intervention } \\
\text { affect funding for similar } \\
\text { projects? }\end{array}$ & + & - - & & & \\
\hline $\begin{array}{l}\text { Does the intervention } \\
\text { affect government level } \\
\text { awareness of } \\
\text { community/individual } \\
\text { needs? }\end{array}$ & ++ & & $\checkmark \checkmark$ & & \\
\hline $\begin{array}{l}\text { Does the intervention } \\
\text { affect interagency } \\
\text { cooperation? }\end{array}$ & ++ & & & & \\
\hline
\end{tabular}





\section{Figure 1 - Preliminary Survey Instrument (1/4)}

\section{Default Question Block}

In general would you say your health is: (choose only one)
Excellent
Very Good
Good
Fair
Poor

Compared to one year ago, how would you rate your general health now? (choose only one)
Much better than one year ago
Somewhat better than one year ago
About the same as one year ago
Somewhat worse than last year
Much worse than one year ago

The following items are about activities you might do during a typical day. Does your health now limit you in these activities? If so, how much?

\begin{tabular}{|c|c|c|c|}
\hline & \multicolumn{3}{|c|}{ Select Only One } \\
\hline & $\begin{array}{l}\text { Yes, } \\
\text { Limited } \\
\text { a Lot }\end{array}$ & $\begin{array}{l}\text { Yes, } \\
\text { Limited } \\
\text { a Little }\end{array}$ & $\begin{array}{l}\text { No, Not } \\
\text { Limited } \\
\text { at All }\end{array}$ \\
\hline $\begin{array}{l}\text { a. Vigorous activities, such as } \\
\text { running, lifting heavy objects, } \\
\text { participating in strenuous sports }\end{array}$ & O & ○ & $\bigcirc$ \\
\hline $\begin{array}{l}\text { b. Moderate activities, such as } \\
\text { moving a table, pushing a } \\
\text { vacuum cleaner or playing golf. }\end{array}$ & $\bigcirc$ & ○ & $\bigcirc$ \\
\hline c. Lifting or carrying groceries & O & O & $\bigcirc$ \\
\hline $\begin{array}{l}\text { d. Climbing several flights of } \\
\text { stairs }\end{array}$ & ○ & O & $\bigcirc$ \\
\hline e. Climbing one flight of stairs & O & O & $\bigcirc$ \\
\hline f. Bending, kneeling or stooping & O & O & $\bigcirc$ \\
\hline g. Walking more than one mile & O & O & O \\
\hline h. Walking several blocks & ○ & O & $\bigcirc$ \\
\hline i. Walking one block & O & O & $\bigcirc$ \\
\hline j. Bathing or dressing yourself & ○ & O & O \\
\hline
\end{tabular}




\section{Figure 1 - Preliminary Survey Instrument (continued 2/4)}

During the past 4 weeks, have you had any of the following problems with your work or other regular activities as a result of your physical health?

\begin{tabular}{|c|c|c|}
\hline & \multicolumn{2}{|c|}{$\begin{array}{c}\text { Select } \\
\text { Only One }\end{array}$} \\
\hline & Yes & No \\
\hline $\begin{array}{l}\text { a. Cut down on the amount of time you spent on } \\
\text { work or other activities? }\end{array}$ & $\bigcirc$ & 0 \\
\hline $\begin{array}{l}\text { b. Accomplished less work than you might have } \\
\text { liked? }\end{array}$ & $\bigcirc$ & 0 \\
\hline $\begin{array}{l}\text { c. Were limited in the kind of work or other } \\
\text { activities? }\end{array}$ & 0 & 0 \\
\hline $\begin{array}{l}\text { d. Had difficulty performing the work or other } \\
\text { activities (for example, it took extra effort)? }\end{array}$ & $\bigcirc$ & $\bigcirc$ \\
\hline
\end{tabular}

During the past 4 weeks, have you had any of the following problems with your work or other regular daily activities as a result of emotional problems (such as feeling depressed or anxious)?

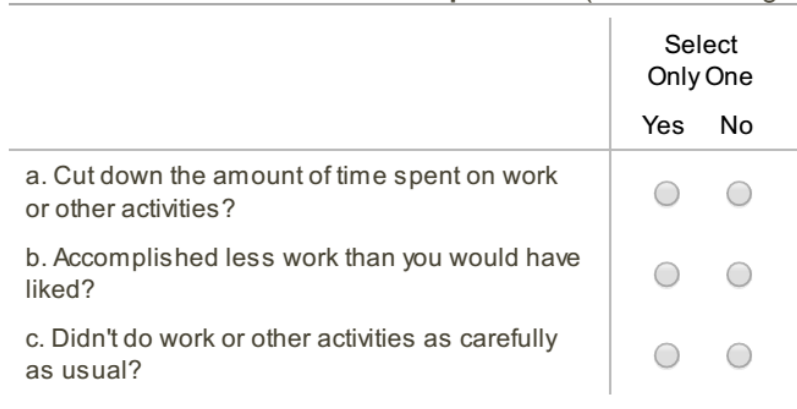

During the past $\mathbf{4}$ weeks, to what extent have your physical health or emotional problems interfered with your normal social activities with family, friends, neighbors or groups? (Select Only One)
Not at all
Slightly
Moderately
Quite a bit
Extremely

How much bodily pain have you had during the past 4 weeks?
None
Very mild
Mild
Moderate
Severe

ᄃ 


\section{Figure 1 - Preliminary Survey Instrument (continued 3/4)}

$\cup$ Verysevere

During the past $\mathbf{4}$ weeks, how much of the time have your physical health or emotional problems interfered with social activities (like visiting with friends, relatives, etc.)?
All of the time
Often
Sometimes
Rarely
Never

How true or false is each statement for you

\begin{tabular}{|c|c|c|c|c|c|}
\hline & Definitely True & Mostly True & Don't Know & Mostly False & Definitely False \\
\hline $\begin{array}{l}\text { My dialysis interferes too } \\
\text { much with my life }\end{array}$ & $\bigcirc$ & ○ & O & ○ & ○ \\
\hline $\begin{array}{l}\text { Too much of my time is } \\
\text { spent dealing with my } \\
\text { dialysis }\end{array}$ & $\bigcirc$ & $\bigcirc$ & 0 & $\bigcirc$ & $\bigcirc$ \\
\hline $\begin{array}{l}\text { I am feeling frustrated } \\
\text { dealing with my dialysis }\end{array}$ & ○ & $\bigcirc$ & ○ & $\bigcirc$ & $\bigcirc$ \\
\hline $\begin{array}{l}\text { I feel like a burden on my } \\
\text { family }\end{array}$ & 0 & 0 & 0 & 0 & 0 \\
\hline
\end{tabular}

Concerning your friends and family, how satisfied are you with:

\begin{tabular}{|c|c|c|c|c|c|c|c|}
\hline & $\begin{array}{c}\text { Very } \\
\text { Dissatisfied }\end{array}$ & Dissatisfied & $\begin{array}{l}\text { Somewhat } \\
\text { Dissatisfied }\end{array}$ & Neutral & $\begin{array}{l}\text { Somewhat } \\
\text { Satisfied }\end{array}$ & Satisfied & $\begin{array}{c}\text { Very } \\
\text { Satisfiec }\end{array}$ \\
\hline $\begin{array}{l}\text { The amount of time you } \\
\text { spend with your family }\end{array}$ & ○ & $\bigcirc$ & $\bigcirc$ & $\bigcirc$ & $\bigcirc$ & $\bigcirc$ & 0 \\
\hline $\begin{array}{l}\text { The support you receive } \\
\text { from your family and } \\
\text { friends }\end{array}$ & $\bigcirc$ & $\bigcirc$ & $\bigcirc$ & $\bigcirc$ & $\bigcirc$ & $\bigcirc$ & $\bigcirc$ \\
\hline
\end{tabular}

During the past 4 weeks, did you work at a paying job?
Yes
No

Does your health keep you from working at a paying job?
Yes
No 


\section{Figure 1 - Preliminary Survey Instrument (continued 4/4)}

Does the time spent with your dialysis treatment keep you from working at a paying job?
Yes
No

How satisfied are you with your current medical transportation service?
Very Dissatisfied
Dissatisfied
Somewhat Dissatisfied
Neutral
Somewhat Satisfied
Satisfied
Very Satisfied

Do you feel that the cost of transportation to and from your dialysis appointments is too high?
Yes
No

Do you feel that you are aware of all the transportation options available to you?
Yes
No

Do you feel confident and in control when deciding how you are going to get to and from your dialysis appointments?
No
Yes 


\subsection{CONCLUSIONS}

We have developed a framework that could be used to evaluate the effectiveness and efficiency of non-emergency transportation services (NEMT), including a hybrid cost-benefit analysis matrix and a preliminary patient survey instrument. In addition to the development of the framework, the project has stimulated an active, ongoing dialogue between the PI and graduate students at PSU with regional partners at Ride Connection, Providence Center for Outcomes Research and Education (Providence CORE), Trimet, Upstream Health and Health Share of Oregon. Research grant proposals involving this newly established regional research network are ongoing as well.

While this project has been successful in creating tools that will be useful for evaluating strategies to improve NEMT, like the one being implemented by Ride Connection, more work still needs to be done in order to ensure the successful application of these tools. Once Ride Connection's pilot project is completed it will be possible to do a thorough analysis using these tools and make modifications as needed. This, in turn, will ensure the adaptability of these tools and their continued usefulness in enhancing transportation for everyone in the community. 


\subsection{REFERENCES}

Bogren, S. (2011). The dialysis report: transportation demand outstrips supply. Community Transportation Association of America.

Burkhardt, J., Koffman, D. \& Murray, G. (2003). Report 91: Economic benefits of coordinating human service transportation and transit service. Transit Research Board.

Burkhardt, J.E. (2006). Medical Transportation: Challenges of the future. Community Transportation. 24, no. 4.

Designing and operating cost-effective Medicaid non-emergency transportation programs. (1998). Healthcare Finance Administration and the National Association of State Medicaid Directors’ Non-Emergency Transportation Technical Advisory Group

Hughes-Cromwick, P., Wallace R., Mull H., \& Bologna J. (2005). Cost benefit analysis of

Kim, J., Norton, E.C. \& Stearns, S.S. (2009). Transportation brokerage services and Medicaid beneficiaries’ access to care. Health Services Research. 44(1), 145-161.

McCann, J. \& Nichols, J. (2005). Medical transportation toolkit and best practices. Community Transportation Association of America.

Minnesota Council on Transportation Access (MCTOA) Annual Report. (2013). Minnesota Department of Transportation.

Non-emergency Medicaid transportation: How to maximize safety and cost effectiveness through better use of private for-hire vehicle operators. (2009). TLPA (Taxicab, Limousine \& Paratransit Association)

Nutt, P.G., Atchley, L., Huddleston, D., Clark, M., Hewlett, T. \& Hood, J. (2000). Progress report on coordinated human service transportation program. (Report no. 298). Frankfort, Kentucky.

Nelson and Nygard Associates. (2012). Coordinated transportation plan for elderly and people with disabilities. Trimet.

Nelson and Nygard Associates. Rhode Island Human Service Transportation Study. Rhode Island Public Transit Authority.

Non-emergency medical transportation (NEMT) study. (2008). The Hilltop Institute. 
O’Connell, L., Siria, B., Grossardt, T. (2002). Bringing fixed-route transit service to small cities and towns: Potential contributions of existing demand-response brokerages. Transportation Research Record. No. 1791, 72-77.

Pagano, A., Metaxatos, P. and King, M. (2002). Effect of computer-assisted scheduling and dispatching systems on paratransit service quality. Transportation Research Record. No. 1791,

Rosenbaum, S., Lopez, N., Morris, M. \& Simon, M. (2009). Medicaid medical transportation assurance: origins, evolution, current trends and implications. George Washington University, Washington D.C.

Stefl, G. \& Newsom, M. (2003). Medicaid non-emergency transportation: national survey 20022003. National Consortium on the Coordination of Human Services Transportation

Stevens, K., Rogers, P. \& Boymal, J. (2008). Evaluation of the Strong Families and Community Strategy 2000-2004. RMIT University Circle.

Stevens, K., Rogers, P. \& Boymal, J. (2009). Qualitative cost-benefit evaluation of complex, emergent program. Evaluation and Program Planning, 32, 83-90.

Tonelli, M., Manns, B., Culleton, B., Klarenbach, S., Hemmelgarn, B., Wiebe, N. \& Gill, J. (2007). Association between the proximity to the attending nephrologist and mortality among patients receiving hemodialysis. CMAJ. 177 (9), 1039—44

Wallace R., Hughes-Cromwick, P., Mull H. \& Snehamay K. (2005). Access to non-emergency medical care and nonemergency medical transportation: two missing links. Transportation Research Record: Journal of the Transportation Research Board. No. 1924, 76-84

Wallerstein, N. and Duran, B. (2010). Community based participatory research contributions to intervention research: The intersection of science and practice to improve health equity. American Journal of Public Health. 100 (S1), S40-S46.

Wilkins, H., Cohen, E. and Tannebaum, M. (2012). How low-income residents decide between emergency and primary health care for non-urgent treatment. The Howard Journal of Communication. 23, 157-174.

Zhao, Z. (2013). Calculating benefits of transit coordination: Minnesota case studies. Minnesota Council on Transportation Access.

Ziller, A. \& Phibbs, P. (2012). Integrating social impacts into cost-benefit analysis: a participative method: case study: the NSW area assistance scheme. Impact Assessment and Project Appraisal, 21:2, 141-146. 